\title{
Philadelphia Chromosome Negative
}

National Cancer Institute

\section{Source}

National Cancer Institute. Philadelphia Chromosome Negative. NCI Thesaurus. Code C128844.

Indicates that the Philadelphia chromosome abnormality, $\mathrm{t}(9 ; 22)(\mathrm{q} 34 ; \mathrm{q} 11)$, has not been detected in a sample. 